\title{
Photoinduced electron transfer reactions across rigid linear spacer groups of high symmetry
}

\author{
Kew-Yu Chen, ${ }^{\mathrm{b}}$ Tahsin J. Chow, ${ }^{\mathrm{a}, *}$ Pi-Tai Chou, ${ }^{\mathrm{b}, *}$ Yi-Ming Cheng ${ }^{\mathrm{b}}$ and Sheng-Heng Tsai ${ }^{\mathrm{a}}$ \\ anstitute of Chemistry, Academia Sinica, 115 Taipei, Taiwan, ROC \\ ${ }^{\mathrm{b}}$ Department of Chemistry, National Taiwan University, 106 Taipei, Taiwan, ROC
}

Received 6 August 2002; revised 5 September 2002; accepted 6 September 2002

\begin{abstract}
A series of highly symmetrical dienes 1-3 were prepared through [2+2] cyclo-addition of norbornadiene (NBD) in an exo-trans-exo geometry. These molecules can be utilized as spacer groups in donor(D)-spacer(S)-acceptor(A) types of electronic dyads possessing strictly linear rigidity. The electronic coupling between D and A was promoted effectively by the $\sigma$-bonds through the all-trans spacer groups so that a highly efficient photoinduced electron transfer process takes place. The even-odd NBD dependent alternation of the $\mathrm{D} / \mathrm{A}$ orientation is intriguing, which leads to an unusual correlation in the spacer tuning electron transfer process. (C) 2002 Elsevier Science Ltd. All rights reserved.
\end{abstract}

Long range intramolecular electron transfer (ET) reaction has been the subject of intensive study for its direct relationship with the redox processes in photosynthesis and certain biological systems. ${ }^{1,2}$ In recent years, electron donor (D)-acceptor (A) chromophores linked by rigid, covalent spacers (S), forming D-S-A dyads, have attracted considerable attention due to their potential applications in the design of molecular devices, among which are molecular rectifiers, ${ }^{3}$ switches,${ }^{4}$ electrochemical sensors, ${ }^{5}$ photovoltaic cells, ${ }^{6}$ and nonlinear optical materials, ${ }^{7}$ etc. Spacer groups that have been utilized are versatile, including small molecules, e.g. cyclohexane,${ }^{8}$ adamantane,${ }^{2}$ bicycle[2.2.2] octane, ${ }^{9}$ steroids, ${ }^{10}$ and oligomers of various sizes, e.g. polynorbornanes, ${ }^{11}$ and ladderanes, ${ }^{12}$ etc. Among numerous types of spacers, rigid linear rod-shaped structures, however, are not commonly observed. ${ }^{13,14}$ The highly symmetrical structures reduce the complexity which is due to geometrical and conformational variations. In this study, we report the preparation of a series of linear, rigid, rod-shaped molecules based on an exo-trans-exo configuration of norbornanes. Both D and A groups are then attached onto the terminals of these bridging molecules with a fixed linear conformation. Preliminary spectroscopic and dynamic studies on ET processes have been performed in various solvents. The intriguing 'all-trans

\footnotetext{
Keywords: rigid rod spacer; electron transfer; donor and acceptor; naphthalene; norbornadiene.

* Corresponding authors. E-mail: tjchow@chem.sinica.edu.tw; chop@ccms.ntu.edu.tw
}

rule' as well as a $\mathrm{D} / \mathrm{A}$ orientation governed ET process are reported herein.

Dimerization and trimerization of norbornadiene (NBD) were accomplished though a prototypical $\mathrm{Co}_{2}(\mathrm{CO})_{6}\left(\mathrm{PPh}_{3}\right)_{2}$ catalyzed reaction. ${ }^{15}$ Compounds 1 and 2 were then purified by column chromatography (eluent: $n$-hexane), followed by recrystallization in hexanes and distillation under reduced pressure. Syntheses of 3 using $\mathrm{Ni}(\operatorname{cod})_{2}$ as a catalyst have been reported with a yield as low as 3\%. Alternatively, 3 was prepared via dimerization of 1 upon UV photolysis in the presence of cuprous triflate, ${ }^{16}$ increasing the yield to $\sim 30 \%$. Compounds 1, 2 and 3 represent the first three members of NBD oligomers sharing the same characteristic of all NBD units being connected by an exo-trans-exo geometry. For the application as spacers, the length of the structure can be finely tuned via adding different numbers of NBD units so that upon the elongation of molecular sizes, the geometry maintains linearity with two terminal double bonds being parallel and equivalent in symmetry. Electron donor and acceptor groups were then added to molecules 1- $\mathbf{3}$ to form the respective dyads. A naphthalene moiety was fused onto the double bond by placing 1 through a reaction with tetrabromo- $o$-xylene according to a known procedure. ${ }^{17}$ Compound 4 obtained was then subjected to another [2+2] cycloaddition with dimethyl acetylenedicarboxylate (DMAD), catalyzed by $\mathrm{RuH}_{2}(\mathrm{CO})\left(\mathrm{PhPh}_{3}\right)_{3}$, to give 5 in $85 \%$ yield. ${ }^{18}$ The same reaction sequence was applied onto $\mathbf{2}$, while $\mathbf{6}$ and 7 were prepared subsequently. 

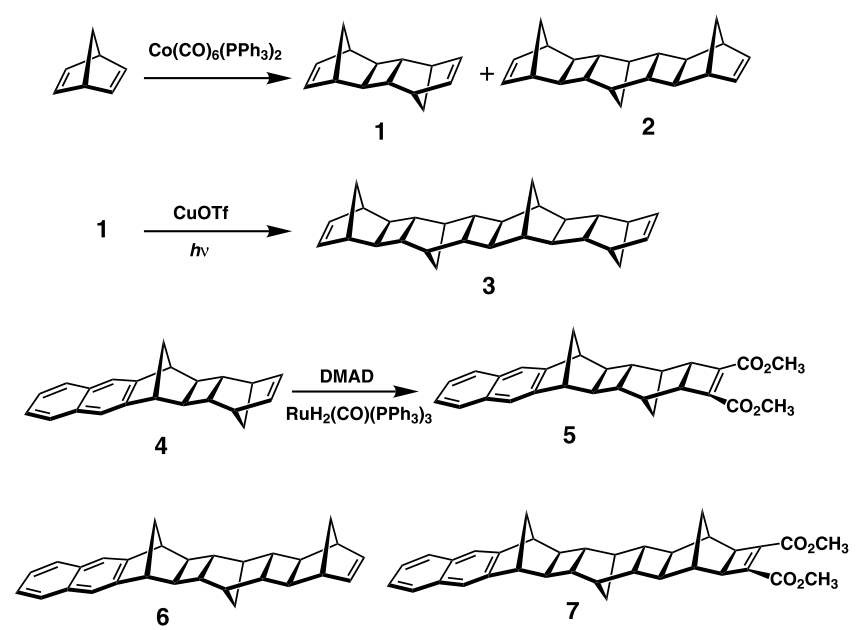

The absorption spectra of 4-7 exhibit a typical characteristic of the naphthalene chromophore. The two absorption bands at 250-290 and 300-330 nm with vibronic progressions are ascribed to ${ }^{1} \mathrm{~L}_{\mathrm{a}}$ and ${ }^{1} \mathrm{~L}_{\mathrm{b}}$ transitions, respectively, of the naphthalene moiety (Fig. 1). The absorption of 1,2-dimethoxycarbonylethyl moiety exhibits an onset at $\sim 260 \mathrm{~nm}$, which should cause negligible interference upon $>266 \mathrm{~nm}$ excitation. As shown in Fig. 1, in comparison to $\mathbf{6}$, the naphthalenelike fluorescence $\left(\lambda_{\max } \sim 335 \mathrm{~nm}\right)$ in THF was substantially reduced in 7 where a $\mathrm{D} / \mathrm{A}$ pair is incorporated, indicating that the ET process is operative in the excited state. Further evidence is given by the resolution of a charge transfer (CT) band for 7 maximized at $\sim 500 \mathrm{~nm}$ in THF. The peak frequency of the CT band shows strong solvent-polarity dependence (see insert of Fig. 1), being red shifted by $\sim 1800 \mathrm{~cm}^{-1}$ from THF to $\mathrm{CH}_{2} \mathrm{Cl}_{2}$.

The excited-state relaxation dynamics were measured by a time-correlated photon counting system described previously, ${ }^{19}$ rendering a temporal resolution of $\sim 15$ ps. The dynamics of decay (or rise) of $\mathbf{5}$ and $\mathbf{7}$ for both normal $\left(\mathrm{F}_{1}\right)$ and $\mathrm{CT}\left(\mathrm{F}_{2}\right)$ bands are listed in Table 1. As shown in Fig. 2 and Table 1, the lifetime of the $F_{1}$ band, within experimental error, correlates well with the rise time of the $F_{2}$ band, unambiguously supporting the photoinduced ET process. Table 1 also lists kinetic data for the corresponding non-ET-transfer models 4 and 6 . The rate of ET, $k_{\mathrm{ET}}$, can thus be calculated by the equation $k_{\mathrm{ET}}=1 / \tau(\mathrm{D} / \mathrm{A})-1 / \tau(\mathrm{D})$ where $\tau(\mathrm{D} / \mathrm{A})$ and $\tau(\mathrm{D})$ denote the lifetime of the $\mathrm{F}_{1}$ (normal) band for molecules possessing $\mathrm{D} / \mathrm{A}$ and $\mathrm{D}$ functional groups, respectively. Alternatively, the ET rate constant can be accessed by a Stern-Volmer equation expressed as $k_{\mathrm{ET}}^{\prime}=\left\{\left[\Phi_{\mathrm{f}}(\mathrm{D}) / \Phi_{\mathrm{f}}(\mathrm{D} / \mathrm{A})\right]-1\right\}\left(1 / \tau(\mathrm{D})\right.$ where $\Phi_{\mathrm{f}}$ is the fluorescence yield of the $\mathrm{F}_{1}$ band. The results listed in Table 1 for $k_{\mathrm{ET}}$ are $k_{\mathrm{ET}}^{\prime}$ show the same trend: an increase in the ET rate upon increasing the solvent polarity. The systematically smaller $k_{\mathrm{ET}}^{\prime}$ values probably result from traces of naphthalene precursors existing in the $\mathrm{D} / \mathrm{A}$ dyads. Due to the very weak $\mathrm{F}_{1}$ intensity in the studied $\mathrm{D} / \mathrm{A}$ dyads, any emission caused by traces of the precursor impurity may interfere with steady-state analyses.

In comparison to previously reported NBD systems, two intriguing remarks can be pointed out. Firstly, the increase in the ET rate was generally observed in these exo-trans-exo systems. The free-energy change $(\Delta G)$ for photo-induced ET between an excited donor molecule (D*) and a ground-state acceptor (A) at a distance $(d)$ can be expressed as:

$$
\begin{aligned}
\Delta G(d)= & E_{\mathrm{ox}}(\mathrm{D})-E_{\mathrm{red}}(\mathrm{A})-E_{00}(\mathrm{D})-\left(e^{2} / \varepsilon d\right)-\left(e^{2} / 2\right)\left(1 / r_{\mathrm{D}}^{+}\right. \\
& \left.+1 / r_{\mathrm{A}}^{-}\right)(1 / 37-1 / \varepsilon)
\end{aligned}
$$

where $E_{\text {ox }}(\mathrm{D})$ and $E_{\text {red }}(\mathrm{A})$ are the oxidation and reduction potentials of $\mathrm{D}$ and $\mathrm{A}$ molecules in acetonitrile, respectively, $E_{00}(\mathrm{D})$ is the energy of zero-zero transition, $r_{\mathrm{D}}{ }^{+}$and $r_{\mathrm{A}}{ }^{-}$are effective ionic radii, $\varepsilon$ is the dielectric constant of solvent, and $d$ is the center-to-center distance between D and A. For example, $E_{\text {ox }}$ and $E_{\text {red }}$ for 6 and 7 were measured to be 1.60 and $-1.50 \mathrm{~V}$,

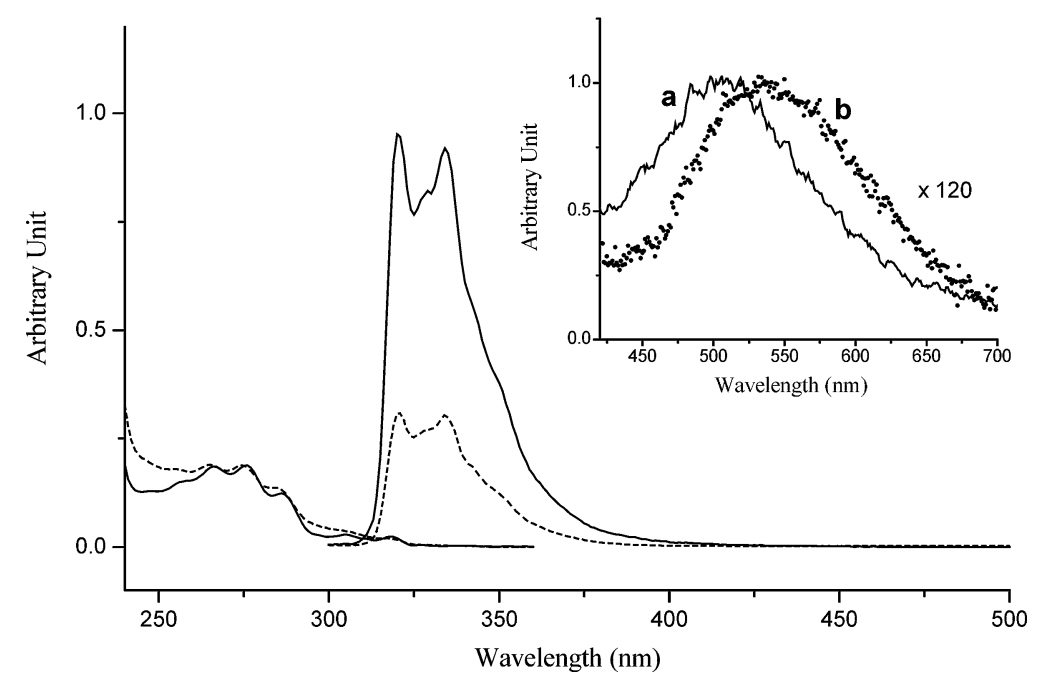

Figure 1. The absorption and emission spectra of compounds 6 (-) and 7 (---) in THF. The absorption spectra are normalized at $\sim 290 \mathrm{~nm}$, whereas the emission spectra are shown in proportion to their relative intensities. Insert: the appearance of a weak CT fluorescence in (a) THF, and (b) $\mathrm{CH}_{2} \mathrm{Cl}_{2}$. 
Table 1. The relaxation dynamics of the fluorescence ${ }^{\mathrm{a}}, k_{\mathrm{ET}}, k_{\mathrm{ET}}^{\prime}$ and free energies $(\Delta G)$ of the ET reaction for $4-7$ in various solvents

\begin{tabular}{|c|c|c|c|c|c|c|c|c|c|}
\hline & $\tau(4)(\mathrm{ns})$ & $\tau(\mathbf{5})(\mathrm{ns})$ & $\Delta G(\mathbf{5})(\mathrm{eV})$ & $k_{\mathrm{ET}}\left(\mathrm{s}^{-1}\right)^{\mathrm{c}}$ & $\tau(\mathbf{6})(\mathrm{ns})$ & $\tau(7)(\mathrm{ns})$ & $\begin{array}{l}k_{\mathrm{ET}}\left(k_{\mathrm{ET}}^{\prime}\right) \\
\left(\mathrm{s}^{-1}\right)\end{array}$ & $\Delta G(7)(\mathrm{eV})$ & $\Delta G(\mathbf{8})^{\mathrm{d}}(\mathrm{eV})$ \\
\hline $\mathrm{Et}_{2} \mathrm{O}$ & 40.83 & $\begin{array}{l}\mathrm{F}_{1}: 0.18 \\
\mathrm{~F}_{2}: 0.14 \\
\text { (rise) } \\
3.78\end{array}$ & -0.11 & $5.53 \times 10^{9}$ & 56.5 & $\begin{array}{l}\mathrm{F}_{1}: 13.94 \\
\mathrm{~F}_{2}: 12.2 \\
\text { (rise) } \\
13.2\end{array}$ & $\begin{array}{l}5.41 \\
(1.86) \times 10^{7}\end{array}$ & -0.07 & -0.24 \\
\hline EtOAc & 60.55 & $\begin{array}{l}\mathrm{F}_{1}: 0.12 \\
\mathrm{~F}_{2}: 0.15 \\
\text { (rise) } \\
3.28\end{array}$ & -0.27 & $8.32 \times 10^{9}$ & 51.16 & $\begin{array}{l}\mathrm{F}_{1}: 8.32 \\
\mathrm{~F}_{2}: 7.31 \\
\text { (rise) } \\
9.78\end{array}$ & $\begin{array}{l}10.08 \\
(4.34) \times 10^{7}\end{array}$ & -0.23 & -0.38 \\
\hline THF & 57.88 & $\begin{array}{l}\mathrm{F}_{1}: 0.10 \\
\mathrm{~F}_{2}: 0.09 \\
\text { (rise) } \\
3.04\end{array}$ & -0.34 & $9.98 \times 10^{9}$ & 57.07 & $\begin{array}{l}\mathrm{F}_{1}: 6.78 \\
\mathrm{~F}_{2}: 6.31 \\
\text { (rise) } \\
9.66\end{array}$ & $\begin{array}{l}13.01 \\
(8.41) \times 10^{7}\end{array}$ & -0.30 & -0.45 \\
\hline $\mathrm{CH}_{2} \mathrm{Cl}_{2}$ & 36.83 & $\begin{array}{l}\mathrm{F}_{1}: 0.085 \\
\mathrm{~F}_{2}: 2.31^{\mathrm{b}}\end{array}$ & -0.39 & $1.2 \times 10^{10}$ & 48.10 & $\begin{array}{l}\mathrm{F}_{1}: 2.25 \\
\mathrm{~F}_{2}: 1.95 \\
\text { (rise) } \\
3.73\end{array}$ & $\begin{array}{l}42.5 \\
(31.3) \times 10^{7}\end{array}$ & -0.35 & -0.50 \\
\hline
\end{tabular}

The free energy of ET in compound $\mathbf{8}(\Delta G(\mathbf{8}))$ is listed for comparison

${ }^{a}$ All measurements were performed in the degassed solution.

${ }^{\mathrm{b}}$ Rise dynamics could not be resolved due to the weak signal.

${ }^{\mathrm{c}} k_{\mathrm{ET}}^{\prime}$ is not available due to the presence of traces of naphthalene precursor.

${ }^{\mathrm{d}}$ Data from Ref. 21.

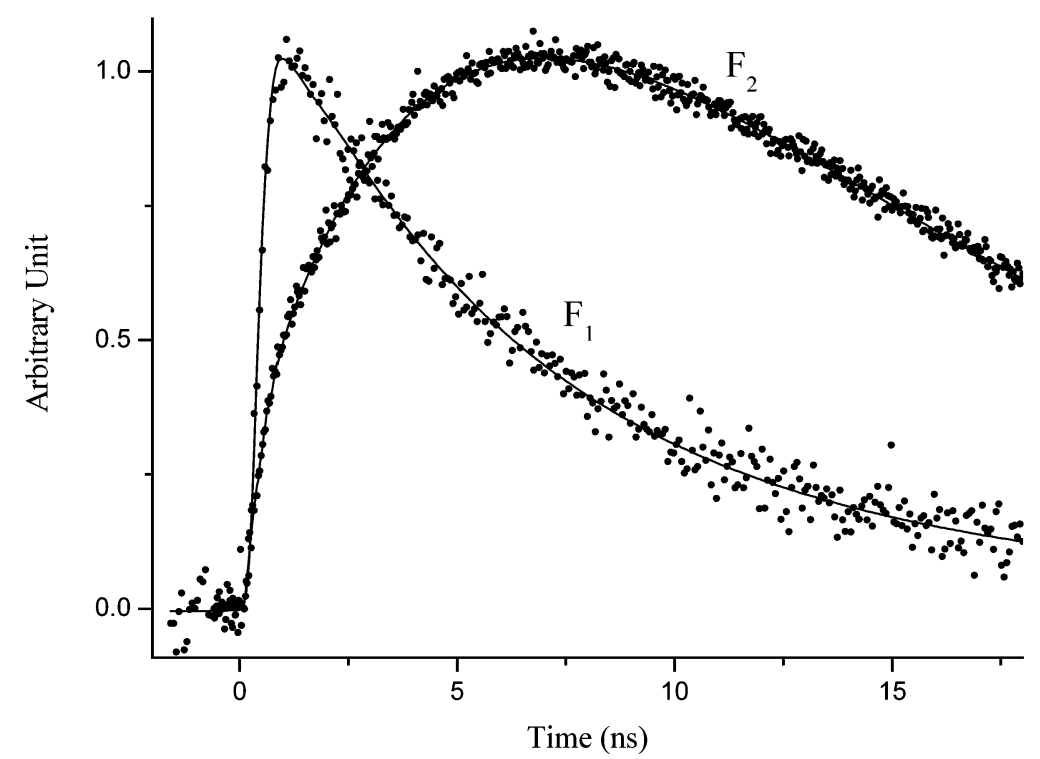

Figure 2. The time-dependent fluorescence of $\mathrm{F}_{1}$ and $\mathrm{F}_{2}$ bands for 7 in THF $\left(\lambda_{\mathrm{ex}}=266 \mathrm{~nm}\right)$. For $\mathrm{F}_{1}: \tau=6.8 \mathrm{~ns}, \mathrm{~F}_{2}: \tau($ rise $)=6.31$ $\mathrm{ns}, \tau($ decay $)=9.66 \mathrm{~ns}$.

respectively in $\mathrm{CH}_{3} \mathrm{CN}$. $E_{00}$ was obtained from the absorption edge of UV spectrum at $318 \mathrm{~nm}(3.91 \mathrm{eV})$. An approximation was further made on $r=r_{\mathrm{D}}{ }^{+}=r_{\mathrm{A}}{ }^{-}=$ 4.5 A. $^{20}$ Consequently, the center-to-center distance between $\mathrm{D}$ (midpoint of the central bond of naphthalene) and A (midpoint of the line connecting the carbonyl carbons) of 7 was estimated to be $14.7 \AA$. With all of the values substituted into Eq. (1), the free energies of $\operatorname{ET~}(\Delta G)$ for 7 (or 5) were calculated and shown in Table 1.
The kinetic data were compared with an analogous system published previously. The structure of $\mathbf{8}$ is similar to that of 7, yet with only eight $\sigma$-bonds intervening between the $\mathrm{D}$ and $\mathrm{A}$ chromophores. In THF, the rate of ET measured for 7 was about twice as fast as those reported for $\mathbf{8}\left(6.5 \times 10^{7} \mathrm{~s}^{-1}\right),{ }^{21}$ albeit a more endergonic reaction was expected for 7 (see Table 1 for comparison), and the $\mathrm{D}-\mathrm{A}$ distance of $7(14.7 \AA)^{22}$ is even longer than that of $\mathbf{8}$ (11.4 $\AA$ due to a bent shape). Although differences in the inner shell nuclear motion 
cannot be neglected, the results may implicate the differentiation in the through $\sigma$-bond overlap, and hence the differences in the electron coupling matrix, between $\mathbf{7}$ and $\mathbf{8}$. It is well known that electron tunneling can be effectively accelerated through coupling with the $\sigma$ bonds of the spacer group. The highly symmetrical geometry of 1-3 fits the 'all-trans rule' in a nearly perfect fashion, which may account for the higher efficiency of ET appearing in $7 .^{23}$ This phenomenon was not unprecedented though, since a recent report showed that photo-induced ET in $\mathbf{1 0}$ proceeded with five orders of magnitude faster than that predicted for 9. ${ }^{24}$ With the same number of intervening $\sigma$-bonds ( 10 for each), the little variation in the geometries of 9 and 10 can result in an enormous difference in the rates of ET processes.
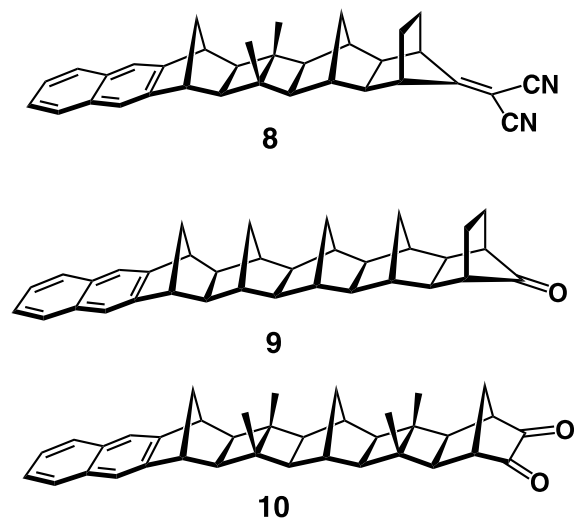

In another approach, it is interesting to note that under the same solvent polarity, e.g. in THF, the ET rate $\left(\sim 1.0 \times 10^{10} \mathrm{~s}^{-1}\right)$ in $\mathbf{5}$ is ca. two orders of magnitude as fast as that in $7\left(1.3 \times 10^{8} \mathrm{~s}^{-1}\right)$. Empirically, the electron coupling matrix $H_{\mathrm{el}}$ can be estimated by $H_{\mathrm{el}}=H_{\mathrm{el}}{ }^{0} \exp [-$ $\left.\beta\left(d_{\mathrm{cc}}-d_{0}\right)\right]^{25}$ where $\beta$ is a measure of the ability of orbitals to extend into space and interact with another orbital, $d_{\mathrm{cc}}$ and $d_{0}$, denote the actual center-to-center separation distance and van der Waals distance or separation distance within the encounter complex, respectively. For D/A dyads with the same configuration of the NBD bridge, the addition of one more NBD distance generally leads to an increment of ca. one order in the rate of the ET reaction published by Paddon-Row and co-workers. ${ }^{26}$ Certainly, an NBD unit (2- $\sigma$-bonds) in Paddon-Row's is different from an 'NBD' unit (3- $\sigma$-bonds) in the series studied here due to the way NBD is fused. Nevertheless, except for the distance of separation, there are also other parameters that might affect the interaction between two chromophores. Spin changes, symmetry factors, and the relative orientation of two reactants may influence the magnitude of $H_{\mathrm{el}}$. For the exo-trans-exo system reported in this study, depending on even or odd number of the NBD unit, the orientation between D and A is expected to switch alternatively between 0 and $\sim 60^{\circ}$. Accordingly, it is plausible that the unusually large difference in the ET rate, in part, may result from the relative difference in the $\mathrm{D} / \mathrm{A}$ orientation between $\mathbf{5}$ and 7. However, since derivation of $H_{\mathrm{el}}$ depends sensibly on the shape, nodal character, and mutual orientation of the orbitals and is even more complicated in the excited state, detailed calculations were not performed in this preliminary study.

In conclusion, a series of highly symmetrical dienes 1-3 were prepared through [2+2] cyclo-addition of NBD in exo-trans-exo geometry. These molecules can be utilized as spacer groups in the D-S-A type of electronic dyads possessing a strictly linear rigidity. The electronic coupling between D and A was promoted effectively by the $\sigma$-bonds through the all-trans spacer groups so that a highly efficient photoinduced ET process takes place. The linearity of the dyads should also be a key-contributing factor to the ET efficiency in comparison to previously reported bent structures. This, in combination with the even-odd NBD dependent alternation of the $\mathrm{D} / \mathrm{A}$ orientation, initiates a perspective aiming at elongating the exo-trans-exo system so that a detailed insight of the ET dynamics can be examined. Design and syntheses toward this goal are currently in progress.

\section{Acknowledgements}

Financial support from the National Science Council of the Rep. of China is gratefully acknowledged. T.J.C. appreciates a visiting scholarship from the Institute for Fundamental Research of Organic Chemistry at Kyushu University during the preparation of this manuscript.

\section{References}

1. (a) Speiser, S. Chem. Rev. 1996, 96, 1953 and references cited therein; (b) Wasielewski, M. Chem. Rev. 1992, 92, 435 .

2. Balzani, V.; Juris, A.; Venturi, M. Chem. Rev. 1996, 96, 759 .

3. (a) Metzger, R. M. J. Mater. Chem. 2000, 10, 55; (b) Scheib, S.; Cava, M. P.; Baldwin, J. W.; Metzger, R. M. J. Org. Chem. 1998, 63, 1198; (c) Aviram, A.; Ratner, M. A. Chem. Phys. Lett. 1974, 29, 277.

4. (a) Chen, J.; Reed, M. A.; Rawlett, A. M.; Tour, J. M. Science 1999, 286, 1550; (b) de Silva, A. P.; Gunaratne, H. Q. N.; Gunnlaugsson, T.; Huxley, A. J. M.; McCoy, C. P.; Rademacher, J. T.; Rice, T. E. Chem. Rev. 1997, 97, 1515

5. (a) Yu, C. J.; Chong, Y.; Kayyem, J. F.; Gozin, M. J. Org. Chem. 1999, 64, 2070; (b) Lewis, F. D.; Wu, T.; Zhang, Y.; Letsinger, R. L.; Greenfield, S. R.; Wasielewski, M. R. Science 1997, 277, 673.

6. (a) Gust, D.; Moore, T. A.; Moore, A. L. Acc. Chem. Res. 1992, 26, 198; (b) Roest, M. R.; Verhoeven, J. W.; Schuddeboom, W.; Warman, J. M.; Lawson, J. M.; Paddon-Row, M. N. J. Am. Chem. Soc. 1996, 118, 1762.

7. (a) Boyd, R. W. Nonlinear Optics; Academic: New York, 1992; (b) Prasad, P. N.; Williams, D. J. Introduction to Nonlinear Optical Effects in Molecular and Polymers; Wiley: New York, 1991.

8. (a) Chattoraj, M.; Paulson, B.; Shi, Y.; Closs, G. L.; Levy, D. H. J. Phys. Chem. 1994, 98, 3361; (b) Chattoraj, 
M.; Bal, B.; Closs, G. L.; Levy, D. H. J. Phys. Chem. 1992, 95, 9666.

9. Zimmerman, H. E.; Goldman, T. D.; Hirzel, T. K.; Schmidt, S. P. J. Org. Chem. 1980, 45, 3934.

10. (a) Tung, C. H.; Zhang, L. P.; Li, Y.; Cao, H.; Tanimoto, Y. J. Am. Chem. Soc. 1997, 119, 5348; (b) Agyin, J. K.; Timberlake, L. D.; Morrison, H. J. Am. Chem. Soc. 1997, 119, 7945 .

11. Warrener, R. N. Eur. J. Org. Chem. 2000, 3363.

12. Warrener, R. N.; Pitt, I. G.; Butler, D. N. J. Chem. Soc., Chem. Commun. 1983, 1340.

13. Warrener, R. N.; Abbenante, G.; Kennard, C. H. L. J. Am. Chem. Soc. 1994, 116, 3645.

14. (a) Chiou, N. R.; Chow, T. J.; Chen, C. Y.; Hsu, M. A.; Chen, H. C. Tetrahedron Lett. 2001, 42, 29; (b) Chow, T. J.; Hon, Y. S.; Chen, C. Y.; Huang, M. S. Tetrahedron Lett. 1999, 40, 7799.

15. (a) Hieber, W.; Sedlmeier, J. Chem. Ber. 1954, 87, 789; (b) Arnold, D. R.; Trecker, D. J.; Whipple, E. B. J. Am. Chem. Soc. 1965, 87, 2596.

16. (a) Salomon, R. G. Tetrahedron 1986, 42, 5753; (b) Chebolu, R.; Zhang, W.; Galoppini, E.; Gilardi, R. Tetrahedron Lett. 2000, 41, 2831.

17. (a) Cava, M. P.; Deana, A. A.; Muth, K. J. Am. Chem. Soc. 1959, 81, 6458; (b) Mcomie, J. F. W.; Perry, D. H. Synthesis 1973, 416.

18. (a) Ahmad, N.; Levison, J. J.; Robinson, S. D.; Uttley, M. G. Inorg. Synth. 1974, 15, 45; (b) Kumar, K.; Tepper, R. J.; Zeng, Y.; Zimmt, M. B. J. Org. Chem. 1995, 60, 4051 .
19. Chou, P. T.; Chen, Y. C.; Yu, W. S.; Chou, Y. H.; Wei, C. Y.; Cheng, Y. M. J. Phys. Chem. A 2001, 105, 1731.

20. Oevering, H.; Paddon-Row, M. N.; Heppener, M.; Oliver, A. M.; Cotsaris, E.; Verhoeven, J. A.; Hush, N. S. J. Am. Chem. Soc. 1987, 109, 3258.

21. Kroon, J.; Verhoeven, J. W.; Paddon-Row, M. N.; Oliver, A. M. Angew. Chem., Int. Ed. Engl. 1991, 30, 1358.

22. The distance was measured from the central bond of naphthalene to the mid-point of a line connecting the carbonyl groups. It will be reduced to $13.5 \AA$ if the bond distance was measured to the ethylene double bond.

23. (a) Paddon-Row, M. N. Acc. Chem. Res. 1994, 27, 18; (b) Paddon-Row, M. N.; Shephard, M. J.; Jordan, K. D. J. Phys. Chem. 1993, 97, 1743; (c) Jordan, K. D.; PaddonRow, M. N. Chem. Rev. 1992, 92, 395.

24. Lokan, N.; Paddon-Row, M. N.; Smith, T. A.; Rosa, M. L.; Ghiggino, K. P.; Speiser, S. J. Am. Chem. Soc. 1999, 121, 2917.

25. For example, see: Closs, G. L.; Calcaterra, L. T.; Green, N. J.; Penfield, K. W.; Miller, J. R. J. Phys. Chem. 1986, 90, 3673.

26. For example, see: (a) Oevering, H.; Paddon-Row, M. N.; Heppener, H.; Oliver, A. M.; Cotsaris, E.; Verhoeven, J. W.; Hush, N. S. J. Am. Chem. Soc. 1987, 109, 3258; (b) Paddon-Row, M. N.; Oliver, A. M.; Warman, J. M.; Smit, K. J.; de Haas, M. P.; Oevering, H.; Verhoeven, J. W. J. Phys. Chem. 1988, 92, 6958. 